\title{
HISTORIA DO DIREITO
}

\section{Algumas disposições de direito privado nas corporações italianas de artes e officios}

O desenvolvimento dos estudos historicos, applicados á sciencia do direito, que uiltimamente se fazem com tanto afinco e prudencia; tem revelado certas curiosidades dignas de serem conhecidas.

A esse movimento de investigação, prestam-se admiravelmente os estatutos das corporações de artes e officios, que predominaram na idade média com tal vigor, que um escriptor moderno affirma que no periodo da sua maior expansão, ellas constituiram uma perigosa praga social.

Invadindo quasi todos os campos da actividade humana, sob as suas variadissimas fórmas; em relação as industrias, ellas absorveram-n'as completamente, e dahi, como consequencia, serem os seus estatutos, verdadeiros codigos de direito privado, particularisados aos interesses e relações juridicas de que se occupavam. 
As corporaç̃os de artes e officios, sendo um producto do meio social da época, em que appareceram, tendiam a satisfazer necessidades de ordem juridico-sociaes, e nesse caracter tinham de reflectir fatalmente, o estado momentaneo do direito privado na idade média.

As normas juridicas, que ellas estabeleciam, então como em todo os tempos, eram impostas pelas necessidades da collectividade.

Algumas dessas normas offerecem tanta origina-. lidade, que um estudioso jurista italiano, Grno Arias, as expõe na conhecida revista Il diritto commerciale (2. fasciculo de I904, vol, XXII-pag. I6 I), extrahindo-as de documentos ineditos do "Archivio Bolognese».

Assim, com flagrante violação dos preceitos, que mais tarde deviam presidir as relações economicas do commercio, algumas corporações prohibiam as vendas a credito, especialmente no commercio a retalho.

A's vezes a prohibição, referia-se exclusivamente aos extrangeiros, como acontecia com os curtidores da "Acqua Calda di Spina di Pisa»; outras vezes era geral e absoluta, como em relação aos curtidores de «S. Niccoló di Pisa», finalmente "outras corporações e entre ellas a dos Linaioli dr Bologna», apenas admittiam o credito entre os inscriptos na Arte; e ainda ahi, o credito não era pessoal, porque exigia-se como garantia um certo penhor das vestes, que fossem confeccionadas com o panno.

A prohibição do credito era em certas regiões tão severa, que procurava-se evitar cuidadosamente que a lei fosse illudida, obstando o proprio emprestimo de dinheiro para a compra da mercadoria manufacturada pela corporação; e assim dispunha a corporação dos alfaiates de Bologna, na rubrica «De denariis non mutuandis alicui volenti se iduere.» 
Já então observava-se a immutabilidade e a inviolabilidade das leis economicas, que se ainda não tinham sido formuladas scientificamente, existiam latentes nas relações sociaes, e eram adivinhadas pela consciencia do povo; e demonstra-o a tendencia que se observava em illudir aquellas prohibições, dissimulando-se a concessão do credito por meio de contractos licitos, mas que constituiam verdadeiras simulações.

LATTES, cuja autoridade em assumptos de investigações historico-juridicas só é equiparavel a de GoldsCHIMIDT, assim se exprime sobre esta anomalia: Os motivos de taes restricções devem ser attribuidos á oppor. tunidade de se evitarem possiveis controversias, represalias e fallencias, e bem assim ao intuito de combater a planta damninha da usura que costumava esconder-se sob esses contractos simulados.》 (LATTES Il dirito commerciale negli Estatuti delle citá italiane, pag. I 38).

Nega a segunda dessas rasões o escriptor a que nos referimos a principio,-e isso porque a prohibição dos negocios a credito não era uma tendencia constante das corporaçōes, destinada a combater as taxas elevadas do juro, seguindo os preceitos canonicos; que aliás, em muitos casos mostravam-se complacentes. Accresce que tal prohibição, sobre não ser constante, revelava-se em outros casos, simplesmente relativa a certas pessoas, como ficou dito.

Resta, portanto, como causa unica, a utilidade dos socios pertencentes á corporação, cuja explicação está de accordo em a orgnisação politico-social da época.

Em primeiro logar, é ponto assentado, que para o credito existir e desenvolver-se é necessaria a confiança, em que elle se inspira, e que o sustenta; mas a constituição economica do segundo periodo da idade 
média, era formalmente contraria, sob mais de um aspecto, ao desenvoivimento e a estabilidade da confiança.

O particularismo ou exclusivismo medieval, era o traço caracteristico, que separava os centros economicos, uns dos outros; não por um casual motivo de malquerença, mas pela conveniencia de fortificar o agrupamento dos associados, incutindo a desconfiança contra aquelles que fossem extranhos ao mesmo, e impedindo o commercio internacional, que os podia enfraquecer.

Esta particularidade da época referida, foi minuciosamente estudada pelo mesmo Grvo Artas, em um escripto sobre "La base delle rappresaglie nella cos. tituzione sociale del medio evo» Revista Italiana di sociologia-vol. VII-I e 2.

De um outro lado, descobre-se na organisação interna das corporações, necessidades não menos intensas.

Ao particularismo nacional corresponde na vida intima dos nucleos economicos, o particularismo de classe, ou melhor de profissão, isto é, a tendencia illimitada para procurar vantagens especiaes aos grupos diversos, embora com prejuiso dos grupos collateraes.

A prohibição do credito visava manter o preço baixo dos productos, pois é sabido que nas vendas á credito o commerciante é obrigado a ter em conta os riscos que corre o seu capital: representam um augmento do preço de custo. Considerava-se assim o augmento de preço como prejudicial á inscipiente industria medieval, para a qual a concurrencia era um perigo.

E depois, as limitaçoes do credito tinham tambem como effeito equiparar a situação das pessoas, col- 
locando todas na mesma linha de poder e força economica, ao passo que a liberdade do credito, estabeleceria sensiveis differenças para aquelles que delle gosassem ou pudessem gosar, justificando divisões e superioridades, que se podiam tornar nocivas á vida da corporação.

Vê-se assim que as limitações do credito encontravam raizes, na organisação social das corporações, e portanto, que a primeira das rasões addusidas por LaTres não passava de uma consequencia das necessidades daquella época. $E$ ' certo que com isso evitavam-se as represalias e as fallencias; mas, precisamente porque motivos fundamentaes tornavam grave o perigo resultante de umas e outras.

Mesmo naquellas corporações, que não prohibiam o credito, procurava-se regulamental-o; e é assim que na corporação da seda de Bologna, prescrevia-se que o praso de sua concessão não podia ir além de quatro mezes contados da data da venda.

Havia, entretanto, nessa época uma certa tendencia para favorecer o credito em vantangem das pessoas filiadas ás corporações, ou aos «homens da arte», como então se dizia.

A corporação dos «Bambasari di Bologna», e a dos «Pelliccraia» da mesma cidade, estabeleciam, a primeira, que o contracto de venda, salvo estipulação em contrario, quando o comprador pertencia á corporação, presumia-se feito a praso de quatro mezes; e a segunda, depois de prohibir as vendas a credito, determinava o praso minimo a conceder quando a compra fosse feita por um socio.

$$
* * *
$$


Outras disposições, que dispertam interesse pelo seu antagonismo com o direito privado moderno, são as que dizem respeito ao contracto de sociedade.

$E$ ' frequente vermos uma corporação prohibir terminantemente, que um dos seus membros faça sociedade com algum membro de uma arte differerente; e numerosos exemplos encontram-se nas corporações de medicos, e de pescadores de Veneza; na dos vinhateiros de Prsa, e na das lãs de Siena.

O principal intuito dessa prohibição está em evitar o augmento dos preços em vantagem dos consumidores, e é por isso que ella apparece principalmente em Veneza, onde o Estado exercia uma certa tutela sobre as artes. Por outro lado entendia-se que a diminuição dos preços revertia indirectamente em beneficio dos proprios «homens da arte», pois della resultava augmento das vendas.

Finalmente reapparece ahi a preoccupação de nivelar todos os associados, obstando-se que um obtenha vantagens sobre os outros; e assim o declara expressamente o "Estatiuto da lã de Siena», justificando a medida pelas seguintes expressões; "Para que frau«des e enganos não se possam commetter entre os homens. «da Arte da Lã e para que cessem rixas e escandalos "que poderiam sobrevir PELAS VANTAGENS QUE UM TE"CELÃO ALCANÇASSE SOBRE OUTRO, E AINDA PARA QUE «AS COUSAS SEJAM PERFEITAMENTE IGUAES, TANTO PARA «OS PEQUENOS COMO PARA OS GRANDES... »

A mesma tendencia egualitaria explica diversas disposições reguladoras da compra de materiaes e productos, relativos ás Artes. 
Sob este ponto de vista é caracteristico o «Breve Pisano dei Vinai», prohibindo a compra de vinho importado por mar, a não ser em Pisa, entre as duas pontes; e bem assim só consentindo a venda de vinho grego, depois de descarregado em armazens da cidade, e nelles conservado pelo menos por tres dias.

Impedia-se ainda que quem quer que fosse comprasse vinho no mar, ou em portos de mar, nem no Arno, e nem mesmo a bordo dos navios.

Além da prohibição, obrigava-se ás vezes o associado a um juramento especial, em que promettia cumprir o preceito, e no "Capitolare dei Filacanape», de Veneza, encontra-se a seguinte formula desse jura mento: "Furo ad Evangélia Santa Dei quod a modo «in antea usque ad festum Santi Michaclis prius ven«turum non conparabo nec conparari faciam pisces ne"que volatilia per aliquod ingenium causa revendendi in «terra...»

Outras vezes, com o fim de vigiar a exacta execução da lei, e tornar mais efficaz o monopolio, attribuia-se aos socios a obrigação de se fiscalisarem reciprocamente; impondo-se tambem ao socio que comprasse materiaes o dever de denunciar a sua compra á corporação.

$$
*^{*} *
$$

Muito interessante é ainda o phenomeno juridico de se englobar na responsabilidade dos socios das corporações toda a sua familia; além da solidariedade que ligava normalmente os socios entre si.

A corporaç̃̃o "Arte della Lana Gentile», de Bologna, em seu estatuto de 1303, dispunha: Quod so. «cii teneantur pro socio respondere obligato ocaxione so- 
«cietatis, et maritus teneatur pro uxore et a converso et "pater pro fliiis.»

A solidariedade da familia apparece no Costituto volgare di Siena de I 309, quando se estabelece que, se um cidadão de Siena fugir levando haveres de um outro cidadão; e se elle tiver um filho legitimo varão, que a esse tempo estivesse em sua companhia, este responderia pelo pae.

Crescia de vulto a importancia e extensão de tal solidariedade, quando ella era inspirada pela existencia de um perigo commum; assim em um momento de crise mercantil, naquella mesma cidade, a solidariedade da familia fortificava-se com a solidariedade communal.

O mesmo Lattes, já citado, interpreta esse facto, dizendo que essas normas provêm da primitiva natureza das sociedades mercantis, formadas por parentes; de onde se teria originado a presumpção de que a convivencia de varias pessoas com um patrimonio indiviso, importava em uma associação de trafico.

Contra essa explicação levanta-se a observação de que semelhante solidariedade não apparece exclusivamente em relações mercantis, mas tambem em outros casos, como o da responsabilidade dos artesãos com os seus patrões, onde o escopo pratico real de solidariedade é evidente. A solidariedade do servo com o patrão nasce da necessidade de reprimir as más acções daquelle, e da pobreza do mesmo, que não the pemittiria pagar a multas em que incidisse. (Corporações dos «Fruttaioli» e dos «Strassacoli» de Padua).

Mas, ainda mesmo para as questões commerciaes, a explicação seria insufficiente, porque se fosse esse o verdadeiro motivo, sempre que encontrassemos a sua causa determinante, o facto da solidariedade devia poder ser constatado; entretanto, que se em alguns 
casos ella apparace, em outros não é encontrada, e se ás vezes surge como medida normal, em outras revela-se como regra excepcional de extensão varia e mutavel.

Assim em Padua, nos estatutos que regiam o processo commercial, se estabelecia a indepencia da responsabilidade do filho da do pae, embora dentro de certos limites.

Aqui, portanto, por especiaes razões, que decorrem da utilidade mercantil, não se consagra a solidariedade; o que aliás deveria acontecer, se ella fosse a resultante de uma convicção juridica.

A verdadeira causa dessas disposições, esta, para Gino ArIas, assim como a de outras modalidades da solidariedade nessa época; nas difficuldades e nos perigos do credito; e tem como intuito reforçar a solidariedade interna mercantil na lucta com elementos extranhos.

Os perigos continuos que o commerciante isolado encontrava no credito, naquelle momento historico; eram diminuidos pela solidariedade da familia, que determinava maiores cautelas; e por outro lado avigoravam-se assim com esses expedientes, os centros mercantis isolados, favorecendo o seu natural desenvolvimento.

$$
* *
$$

Do exposto se pode concluir que essas diversas normas juridicas, que se nos afiguram hoje excepcionaes; longe de serem governadas por conceitos juridicos; são inspiradas e têm as suas raizes na constituição da sociedade, e nas funções sociaes, que della recebem vida, tendo como escopo necessidades reaes.

S. Paulo, Março de I905.

Dr. F. Vergueiro Steidel. 